\title{
Genetic diversity and population structure of Ethiopian faba bean (Vicia faba L.) germplasm revealed by ISSR markers
}

\author{
Bullo Neda $a^{a^{*}}$, Tileye Feyissa ${ }^{\text {b,c }}$, Kifle Dagne ${ }^{c}$ Ermias Assefa ${ }^{\mathrm{d}}$ \\ ${ }^{a}$ Department of Plant Science, College of Agriculture and Natural Resource, Salale University, P.O. Box 245, Fitche, Ethiopia \\ ${ }^{b}$ Institute of Biotechnology, Addis Ababa University, P. O. Box 1176, Addis Ababa, Ethiopia \\ 'Department of Microbial, Cellular and Molecular Biology, Addis Ababa University, Addis Ababa, Ethiopia \\ ${ }^{d}$ Ethiopian Biotechnology Institute, Addis Ababa, Ethiopia
}

Received 9th December 2020 / Accepted 12th March 2021

\begin{abstract}
Molecular characterization of faba bean accessions is important for future collection, conservation, and crop improvement programs. However, molecular genetic diversity of the Ethiopian faba bean accessions has not been comprehensively characterized. The present study was conducted to determine the genetic diversity and population structure of 90 faba bean landraces and six released varieties using nine inter-simple sequence repeat (ISSR) markers. The polymorphic information content (PIC), marker index (MI), resolving power (RP) and effective multiplex ratio (EMR) showed average values of $0.32,5.87,7.14$, and 18.34 per primer, indicating high polymorphism values. The marker revealed average gene diversity of 0.26 , ranging from 0.15 to 0.36 . The degree of polymorphism among the landrace accessions ranged from $44.91 \%$ for the Sidama population to $72.46 \%$ for the East Hararghe population, with a mean of $57.27 \%$. Analysis of molecular variance (AMOVA) indicated $99 \%$ variation within and $1 \%$ variation among population, respectively. The present study revealed little to moderate population differentiation accompanied by high gene flow. Both distance-based and model-based cluster analysis distinguished seven distinct groups illustrating the conformity of results obtained from the study. Accessions from different administrative zones (AZs) of the country were distributed over most of the clusters; exhibiting high genetic diversity in collection sites. Therefore, further collection, conservation, and utilization programs would be recommended from AZs with high genetic diversity.
\end{abstract}

Keywords: Analysis of molecular variance, genetic differentiation, gene flow, Neighbor-joining (NJ), Principal component analysis (PCoA)

\section{INTRODUCTION}

The most important cool season food legume in the world are chickpeas, garden pea, lentil, and faba bean (Kaur et al., 2014). The center of origin and primary diversity of faba bean is widely believed somewhere in the Middle East (Lawes et al., 1983). In addition, Harlan (1969) discovered that Ethiopia and Afghanistan are the secondary centers of diversity. Recently, an archaeological study strongly suggests that Neolithic people in Israel first domesticated faba bean 10,000 years ago; and they were eating as a staple food before grain began to be cultivated in the area (Caracuta et al., 2015). The faba bean introduction to Ethiopia was supposed to be from the Middle East via Egypt around 5,000 BC soon after its domestication (Duc et al., 2010). The world-

\footnotetext{
*Author for correspondence: Bullo Neda Tulu, Department of Plant Science, College of Agriculture and Natural Resource, Salale University, P.O. Box245, Fitche, Ethiopia. Email - tulu0913479057@gmail.com
} 
leading producing countries for faba beans are China, Ethiopia, Egypt, and the United Kingdom (FAOSTAT, 2014). Faba bean is grown in mid and highland agro-ecologies of Ethiopia, ranging from 1,800 to 3,000 m.a.s.l.; where the mean rainfall ranges from 650 to $1,500 \mathrm{~mm}$. It serves as a multi-purpose crop leading the pulse category in areas and production (CSA, 2018). Faba bean provides food for humans, maintaining soil fertility through atmospheric nitrogen fixation; it is also used as fodder; a break crop to reduce cereal diseases, insect pests, and weeds (Chintalapati, 2001). The beautiful flowers of faba bean also attract pollinators' insects (Marzinzig et al., 2018).

Faba bean area coverage and production volumes are 443,966 ha and 848,655 tons, respectively of pulses grown in Ethiopia (CSA, 2014). The average yield of faba bean in the world is $5.00 \mathrm{t} / \mathrm{ha}$ (CSA, 2014), however, the average national yield of faba bean in Ethiopia is $2.10 \mathrm{t} / \mathrm{ha}$ (CSA, 2018). Bekele et al. (2006) reported the low yield of faba bean in Ethiopia is due to biological limitation of the crop; particularly the susceptibility to biotic (diseases, insects, and weeds) and abiotic stresses (moisture deficit, high soil acidity, waterlogging, and frost), and also the inherently low yielding potential of indigenous landrace accessions.

One way of mitigating these constraints is by developing sound crop improvement programs that increase the productivity of the crop through the development of varieties resilient to biotic and abiotic constraints. As a result, to increase production and productivity of faba bean; identifying the genetic diversity available in the landrace materials is the pre-requisite for a successful improvement of the crop. To achieve this, studying the molecular characterization of the crop is imperative. However, the molecular genetic diversity of Ethiopian faba bean landrace accessions has not been comprehensively characterized. Tores and Avilla (2011) also reported that more than $80 \%$ of faba bean cultivation is in developing countries where the applications of novel molecular breeding approaches are limited. Hence, it is crucial to further investigate the potential of molecular genetic diversity of the landraces accessions of faba beans in Ethiopia as a source for further breeding work. According to Awan et al. (2014), carrying out genetic diversity assessment on landrace accessions is essential for broadening the genetic base of cultivars, identifying accessions with higher potential for yield, disease resistance, and nutritional qualities to sustain improvement. Inter-simple sequence markers (ISSR) has advantages over other markers that are low-cost, easy to use, and its methodology is easy as compared to other dominant markers; it is also an ideal genetic marker for organisms whose genetic information is lacking, though there are no complete markers in every aspect. Mishra et al. (2003) stated that ISSRs markers are evenly distributed throughout the genome of the organisms, for PCR requires small quantities of template DNA, and it does not need sequence data as that of other markers for primer construction. Therefore, the study aims to determine the molecular genetic diversity and population structure of Ethiopian faba bean landrace accessions collected from different administrative zones (AZs) of Ethiopia using ISSR markers. Furthermore, PIC, MI, RP, and EMR were analyzed to determine the potential of ISSR markers to detect polymorphism of faba bean landrace accessions in Ethiopia.

\section{MATERIALS AND METHODS}

\section{Plant materials}

Seeds of 90 faba bean landrace accessions collected from 14 AZs of Ethiopia were obtained from the Ethiopian Biodiversity Institute (EBI). Furthermore, six released varieties obtained from Holeta Agricultural Research Center (HARC) and Debrabirhan Agricultural Research Center (DbARC) were also included for comparison purposes (Table 1). The potential faba bean growing $\mathrm{AZs}$ of Ethiopia were selected and accessions from each AZ were appropriately represented according to their proportions. Accessions from each AZ were collected from altitudes ranging from 1562-3130 m.a.s.l. and each $\mathrm{AZ}$ is also considered as a pre-defined population. Fifteen seeds per accession were grown in a greenhouse at the College of Natural Science, Addis Ababa University (AAU). The AZs from which collections were done for the landrace accessions are shown in Figure 1. 
Table 1. List of accessions, collection regions, and sites for the 90 faba bean (Vicia faba L.) landrace accessions used in the study including 6 released varieties.

\begin{tabular}{|c|c|c|c|c|c|c|c|}
\hline No. & Region & $\begin{array}{l}\text { Administrative } \\
\text { zone }\end{array}$ & Accession & No. & Region & $\begin{array}{l}\text { Administrative } \\
\text { zone }\end{array}$ & Accession \\
\hline 1 & Amhara & North Shewa A & 212580 & 49 & Oromia & East Hararghe & 29535 \\
\hline 2 & Amhara & North Shewa A & 212572 & 50 & Oromia & East Hararghe & 29533 \\
\hline 3 & Amhara & North Shewa A & 212567 & 51 & Oromia & East Hararghe & 29536 \\
\hline 4 & Amhara & North Shewa A & 229299 & 52 & Oromia & West Shewa & 25270 \\
\hline 5 & Amhara & North Shewa A & 212578 & 53 & Oromia & West Shewa & 25264 \\
\hline 6 & Amhara & North Shewa A & 208114 & 54 & Oromia & West Shewa & 25260 \\
\hline 7 & Amhara & North Shewa A & 208085 & 55 & Oromia & West Shewa & 25259 \\
\hline 8 & Amhara & North Shewa A & 229310 & 56 & Oromia & West Shewa & 25274 \\
\hline 9 & Amhara & North Shewa A & 212565 & 57 & SNNPR & Sidama & 28109 \\
\hline 10 & Amhara & East Gojam & 25017 & 58 & SNNPR & Sidama & 28110 \\
\hline 11 & Amhara & East Gojam & 27279 & 59 & SNNPR & Sidama & 28112 \\
\hline 12 & Amhara & East Gojam & 229871 & 60 & SNNPR & Sidama & 28113 \\
\hline 13 & Amhara & East Gojam & 26428 & 61 & SNNPR & Gedeo & 28104 \\
\hline 14 & Amhara & East Gojam & 25006 & 62 & SNNPR & Gedeo & 26861 \\
\hline 15 & Amhara & East Gojam & 229869 & 63 & SNNPR & Gedeo & 26883 \\
\hline 16 & Amhara & East Gojam & 26400 & 64 & SNNPR & Gedeo & 26859 \\
\hline 17 & Oromia & West Arsi & 30011 & 65 & SNNPR & Gedeo & 26882 \\
\hline 18 & Oromia & West Arsi & 30008 & 66 & SNNPR & Gedeo & 26862 \\
\hline 19 & Oromia & West Arsi & 30014 & 67 & SNNPR & Gedeo & 26885 \\
\hline 20 & Oromia & West Arsi & 30016 & 68 & SNNPR & Gedeo & 26887 \\
\hline 21 & Oromia & West Arsi & 30015 & 69 & SNNPR & Gedeo & 26886 \\
\hline 22 & Oromia & West Arsi & 30017 & 70 & SNNPR & Gedeo & 28103 \\
\hline 23 & Oromia & Arsi & 25009 & 71 & SNNPR & Gedeo & 26860 \\
\hline 24 & Oromia & Arsi & 27052 & 72 & SNNPR & Segen & 26855 \\
\hline 25 & Oromia & Arsi & 231293 & 73 & SNNPR & Segen & 26888 \\
\hline 26 & Oromia & Arsi & 219089 & 74 & SNNPR & Segen & 26854 \\
\hline 27 & Oromia & Arsi & 219355 & 75 & SNNPR & Segen & 26858 \\
\hline 28 & Oromia & Bale & 30023 & 76 & SNNPR & Segen & 26889 \\
\hline 29 & Oromia & Bale & 28777 & 77 & SNNPR & Segen & 26853 \\
\hline 30 & Oromia & Bale & 30022 & 78 & SNNPR & Kembata & 25310 \\
\hline 31 & Oromia & Bale & 28774 & 79 & SNNPR & Kembata & 25303 \\
\hline 32 & Oromia & Bale & 28771 & 80 & SNNPR & Kembata & 25299 \\
\hline 33 & Oromia & Bale & 28776 & 81 & SNNPR & Kembata & 25298 \\
\hline 34 & Oromia & Bale & 28772 & 82 & SNNPR & Kembata & 25290 \\
\hline 35 & Oromia & Bale & 30021 & 83 & SNNPR & Kembata & 25292 \\
\hline 36 & Oromia & Bale & 28770 & 84 & SNNPR & Bench Maji & 27931 \\
\hline 37 & Oromia & Bale & 28773 & 85 & SNNPR & Bench Maji & 235709 \\
\hline 38 & Oromia & North Shewa O & 212566 & 86 & SNNPR & Bench Maji & 27929 \\
\hline 39 & Oromia & North Shewa O & 25022 & 87 & Tigray & Central Tigray & 220079 \\
\hline 40 & Oromia & North Shewa O & 25010 & 88 & Tigray & Central Tigray & 220076 \\
\hline 41 & Oromia & North Shewa O & 25003 & 89 & Tigray & Central Tigray & 16599 \\
\hline 42 & Oromia & North Shewa O & 25018 & 90 & Tigray & Central Tigray & 220086 \\
\hline 43 & Oromia & North Shewa O & 229303 & 91 & Released & Released & Bulga-70 \\
\hline 44 & Oromia & East Hararghe & 29537 & 92 & Released & Released & Lalo \\
\hline 45 & Oromia & East Hararghe & 29531 & 93 & Released & Released & Dagim \\
\hline 46 & Oromia & East Hararghe & 29526 & 94 & Released & Released & Walki \\
\hline 47 & Oromia & East Hararghe & 29527 & 95 & Released & Released & Moti \\
\hline 48 & Oromia & East Hararghe & 29532 & 96 & Released & Released & Hachalu \\
\hline
\end{tabular}

North Shewa A = North Shewa Amhara, North Shewa O = North Shewa Oromia, SNNPR = South Nations Nationalities and Peoples Region 


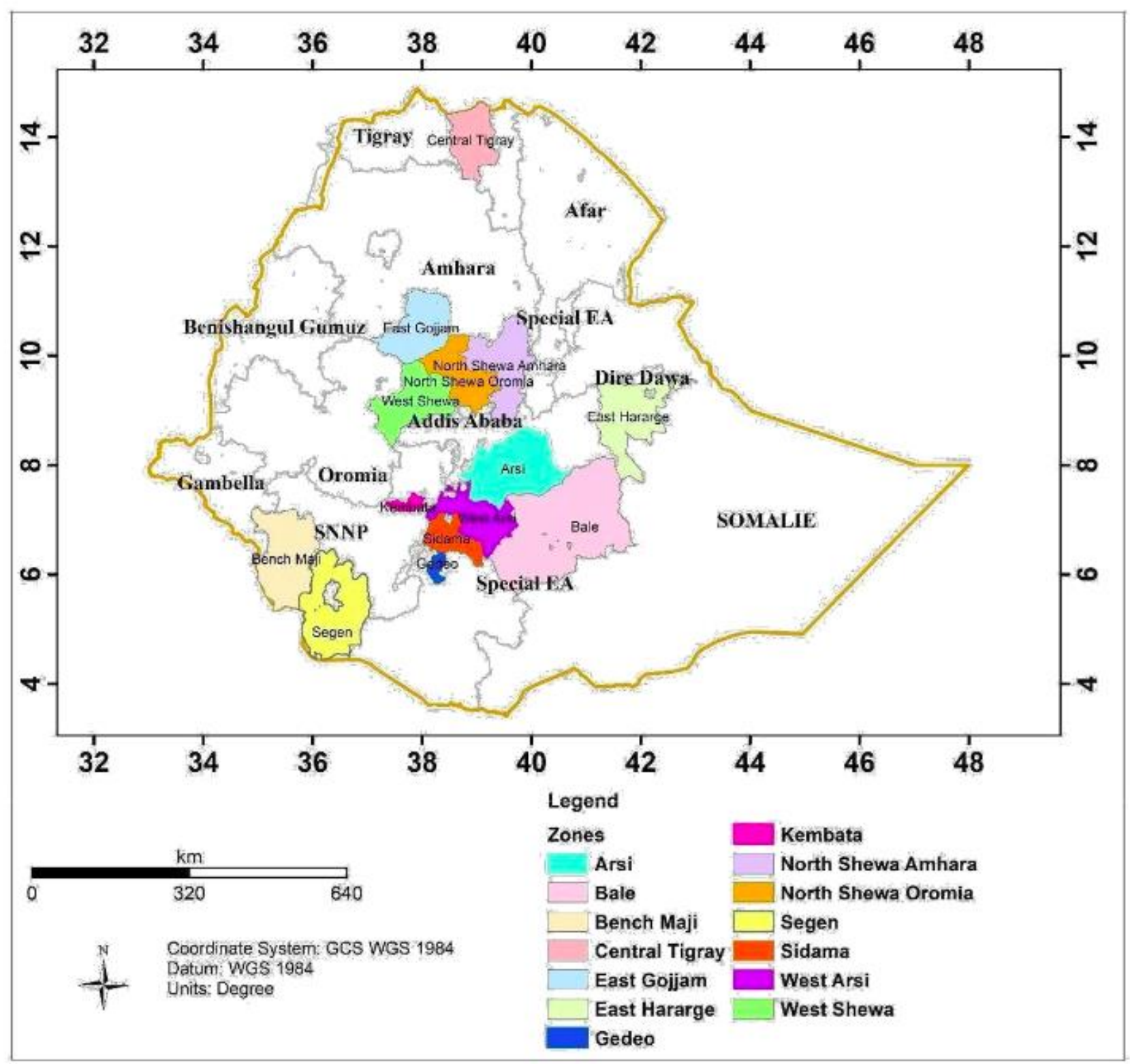

Figure 1. Map of Ethiopia showing the collection AZs of faba bean landrace accessions.

\section{DNA extraction}

Young leaves of ten plants per accession from three-week-old seedlings were randomly selected and dried in silica gel. A method developed by Borsch et al. (2003) was used for total genomic DNA extraction using $50 \mathrm{mg}$ silica gel dried leaf tissue samples of ten plants of each accession. To test optimum quality and quantity of genomic DNA, a modified CTAB method employing triple extraction was executed using 1\% ethidium bromide-stained agarose gel electrophoresis under UV light and NanoDrop spectrophotometer. Based on the quality and quantity of genomic DNA, among the triple extractions, the first extraction was selected for further PCR amplification. So, for PCR amplification, the first extraction of genomic DNA was diluted to $80 \mathrm{ng} / \mu \mathrm{l}$ with sterile distilled water.

\section{PCR and electrophoresis}

The experimental results on faba bean (AbdulRazzak et al., 2012) and other related crops like chickpea (Bhagyawant and Srivastava, 2008) and lentil (Meenakshi et al., 2013) are the basis of the selection of 17 ISSR markers for further screening. Using five representative accessions from populations with high genetic diversity 
based on morphological data, nine ISSR primers that revealed amplification of unambiguously visible and reproducible bands were selected for further analyses (Table 2). The total PCR reaction components volume per sample was $25 \mu \mathrm{l}$; consisting of $17.20 \mu \mathrm{l}$ sterile distilled water, 2.50 $\mu \mathrm{l} \mathrm{MgCl} 2$ (25 mM), $2.50 \mu \mathrm{l}$ 10x PCR buffer, 1.00 $\mu l$ dNTP (100 mM equimolar solution of each dATP, dCTP, dGTP and dTTP), $0.40 \mu l$ primer (20 pmol $/ \mu \mathrm{l}), 0.40 \mu \mathrm{l}$ Taq polymerase $(5 \mathrm{U} / \mu \mathrm{l})$ and $1 \mu \mathrm{l}$ template DNA $(80 \mathrm{ng} / \mu \mathrm{l})$. PCR amplification was carried out using BiometraT3 thermocycler. The initial denaturation was set at $94^{\circ} \mathrm{C}$ for $4 \mathrm{~min}$, denaturation for 40 cycles at $94^{\circ} \mathrm{C}$ for $15 \mathrm{~s}$, annealing temperature for $1 \mathrm{~min}$ ranging from $42^{\circ} \mathrm{C}$ to $48^{\circ} \mathrm{C}$, extension at $72^{\circ} \mathrm{C}$ for $1: 30$ min, and a final extension at $72^{\circ} \mathrm{C}$ for $7 \mathrm{~min}$. Until the time of gel electrophoresis, the PCR products were stored at $4^{\circ} \mathrm{C}$ (Joseph \& David, 2001). Ten $\mu l$ amplification products of each sample were mixed with $2 \mu \mathrm{l}$ of six times concentrated loading dye and loaded on the gel. One hundred base-pair DNA marker was loaded on the first lane of the gel to estimate the sizes of the bands. Electrophoresis was conducted at $100 \mathrm{~V}$ for 2:00 $\mathrm{h}$ in a $1 \mathrm{x}$ TBE buffer. Ethidium bromide (10 $\mathrm{mg} / \mathrm{ml}$ ) mixed with $450 \mathrm{ml}$ distilled water was used to be stained for $30 \mathrm{~min}$ and destained with $450 \mathrm{ml}$ of distilled water for $30 \mathrm{~min}$. The bands were visualized by Camera- fitted Gel Doc. System.

Table 2. Lists of primers, their sequence, repeat motif, annealing temperature and nucleotide.

\begin{tabular}{|c|c|c|c|c|c|}
\hline No. & Primer & Sequence from 5'-3' & $\begin{array}{c}\text { Repeat } \\
\text { Motif }\end{array}$ & $\begin{array}{l}\text { Annealing } \\
\text { temp }\left({ }^{\circ} \mathrm{C}\right)\end{array}$ & Nucleotide types \\
\hline 1 & UBC812 & 5'GAGAGAGAGAGAGAGAG3' & (GA)8G & 45 & Di-nucleotide \\
\hline 2 & UBC815 & 5’СТСТСТСТСТСТСТСТG3' & (CT) $8 \mathrm{G}$ & 42 & Di-nucleotide \\
\hline 3 & UBC824 & 5'ТСТСТСТСТСТСТСТCG3' & (TC) $8 \mathrm{G}$ & 48 & Di-nucleotide \\
\hline 4 & UBC835 & 5'AGAGAGAGAGAGAGAGYC3' & (AG) $8 \mathrm{YC}$ & 48 & Di-nucleotide \\
\hline 5 & UBC840 & 5'GAGAGAGAGAGAGAGAYT3' & (GA)8YT & 42 & Di-nucleotide \\
\hline 6 & UBC841 & 5'GAGAGAGAGAGAGAGAYC3' & $(\mathrm{GA}) 8 \mathrm{YC}$ & 43 & Di-nucleotide \\
\hline 7 & UBC873 & 5'GACAGACAGACAGACA3' & (GACA) 4 & 45 & Tetra-nucleotide \\
\hline 8 & UBC880 & 5'GGAGAGGAGAGGAGA3' & $($ GGAGA)3 & 45 & Penta-nucleotide \\
\hline 9 & UBC881 & 5'GGGTGGGGTGGGGTG3' & (GGGTG)3 & 47 & Penta-nucleotide \\
\hline
\end{tabular}

\section{Data analyses}

Using the binary matrix representing the column as the ISSR bands and rows as the accessions, the bands were scored as present (1), absent (0), or ambiguous (?). The marker informativeness was measured through the counting of bands to determine the potential of the markers for the genetic diversity study of faba bean landrace accessions. Hence, the number of scored bands (NSB), number of polymorphic bands (NPB), number of private bands $(\mathrm{NPvB})$, number of rare bands (NRB), number of common bands (NCB), and number of abundant bands (NAB) were recorded to detect marker informativeness prior to diversity analysis. Besides, PIC, MI, RP, and EMR parameters of the ISSR markers were calculated using GenAIEx 6.5 software (Peakall and Smouse, 2006) to detect the suitability of the markers for the genetic diversity study of faba bean landrace accessions. The population indices such as polymorphic loci $(\mathrm{P})$, observed alleles
$(\mathrm{Na})$, effective alleles $(\mathrm{Ne})$, genetic diversity (GD), Shannon information index (I), expected heterozygosity (h), unexpected heterozygosity (uh), genetic distance (Gd), genetic identity (GI), genetic differentiation (PhiPT), principal component analysis (PCoA), and analysis of molecular variance (AMOVA) were also measured by using GenAIEx 6.5 software (Peakall and Smouse, 2006). The Neighborjoining dendrogram method of Saitou and Nei (1987) has constructed clustering using the $\mathrm{R}$ package POPPR software (Kamvar et al., 2014). Discriminant analysis of principal components (DAPC) was also measured by the Adegenet $\mathrm{R}$ package software (Jombart et al., 2010). STRUCTURE 2.3.4 software was used to calculate population structure (Pritchard et al., 2000). According to Evanno et al. (2005), to assess the exact number of clusters through STRUCTURE HARVESTER (Earl, 2012); a burn-in period of 50,000 with 100,000 MARKOV 
Chain Monte Carlo (MCMC) iterations was run 5 times for each $\mathrm{K}$ value, in our case $\mathrm{K}=1$ to 10 .

\section{RESULTS}

\section{ISSR primers banding patterns and diversity}

The genetic diversity of 90 Ethiopian faba bean landrace accessions collected from 14 AZs including six released varieties were evaluated using nine ISSR markers. Prior to diversity assessment, the suitability of the ISSR markers was evaluated through their efficiency, reliability, and discriminatory power to reveal markers' potential.

Nine ISSR markers revealed 167 total bands, with band size ranging from $133 \mathrm{bp}$ to $3000 \mathrm{bp}$ with all 100\% polymorphism. The largest variation in fragment size was detected for primer UBC815 (333 bp -3000 bp) and the lowest for UBC873 (133 bp - 800 bp). The ISSR markers showed a mean of 18.60 band types per primer, ranging from 14 to 25 . The maximum and the minimum number of bands were amplified by the primer UBC815 (25) and UBC824 (14), respectively. The mean of the $\mathrm{NPvB}$ is 1.40 , ranging from 0 to 4 . Rare bands (NRB) are polymorphic bands that were reported in less than $5 \%$ of the accessions under study. The mean of the NRB is 3.20 per primer, with its total of 29 across accession. Both the largest $\mathrm{NPvB}$ and the largest $\mathrm{NRB}$ of 4 and 7 , respectively were generated by the primer UBC873. Common bands (NCB) are polymorphic bands that were reported in $5-50 \%$ of the accessions. The mean of the NCB is 13.90 per primer, with its total of 125 across accession. Both primer UBC812 and UBC841 amplified the maximum NCB with the value of 21. On the other hand, primer UBC880 and UBC881 amplified the minimum NCB with a value of 9. Abundant bands (NAB) are polymorphic bands that were reported in more than $50 \%$ of the accessions. The mean of NAB is 1.40 per primer, with its total of 13 across accession. The primer UBC881 showed the highest NAB of 6 (Table 3).

Table 3. Number of scored bands, polymorphic bands, percentage of polymorphic bands, private bands, rare bands, common bands, abundant bands and fragment size amplified by nine ISSR primers in faba bean accessions.

\begin{tabular}{|c|c|c|c|c|c|c|c|c|c|c|}
\hline Primer & $\begin{array}{l}\text { Repeat } \\
\text { Motif }\end{array}$ & $\begin{array}{c}\mathrm{T} \\
\left({ }^{\circ} \mathrm{C}\right)\end{array}$ & NSB & NPB & $\% \mathbf{P}$ & NPvB & NRB & NCB & NAB & FS \\
\hline UBC812 & (GA)8A & 45 & 23 & 23 & 100 & 2 & 2 & 21 & 0 & $200-2000$ \\
\hline UBC815 & (CT) $8 \mathrm{G}$ & 42 & 25 & 25 & 100 & 2 & 3 & 20 & 2 & $333-3000$ \\
\hline UBC824 & (TC) $8 \mathrm{G}$ & 48 & 14 & 14 & 100 & 0 & 0 & 13 & 1 & $400-1500$ \\
\hline UBC835 & (AG)8YC & 48 & 17 & 17 & 100 & 2 & 6 & 10 & 1 & $150-1000$ \\
\hline UBC840 & (GA)8YT & 42 & 15 & 15 & 100 & 2 & 1 & 12 & 2 & $300-1500$ \\
\hline UBC841 & (GA) $8 Y C$ & 43 & 24 & 24 & 100 & 0 & 2 & 21 & 1 & $350-1500$ \\
\hline UBC873 & (GACA)4 & 45 & 17 & 17 & 100 & 4 & 7 & 10 & 0 & $133-800$ \\
\hline UBC880 & $($ GGAGA)3 & 45 & 15 & 15 & 100 & 2 & 6 & 9 & 0 & $200-1500$ \\
\hline UBC881 & (GGGTG)3 & 47 & 17 & 17 & 100 & 0 & 2 & 9 & 6 & $350-1400$ \\
\hline Total & & & 167 & 167 & 100 & 13 & 29 & 125 & 13 & - \\
\hline Average & & & & & 100 & 1.40 & 3.20 & 13.90 & 1.40 & - \\
\hline
\end{tabular}

$\mathrm{T}\left({ }^{\circ} \mathrm{C}\right)=$ annealing temperature, $\mathrm{NSB}=$ Number of the scored bands; NPB $=$ Number of polymorphic band; $\% \mathrm{P}=$ percentage of polymorphism; $\mathrm{NPvB}=$ number of private bands; $\mathrm{NRB}=$ number of rare bands; $\mathrm{NCB}=$ number of common bands; $\mathrm{NAB}$ $=$ number of abundant bands, FS = fragment size amplified.

Each accession genetic profile was evaluated through the ISSR marker performances of PIC, MI, RP, and EMR parameters. The highest and the lowest PIC values of 0.44 and 0.19 were exhibited by the primer UBC881 and UBC873, respectively, with the mean value of PIC 0.32
(Table 4). MI indicated the general usefulness of the markers. The highest and the lowest MI values of 7.46 and 3.18 were exhibited by the primer UBC815 and UBC873, respectively, with the mean value of MI 5.87. RP is the discriminatory potential of the markers. Similar to PIC, the 
highest (12.13) and the lowest (2.96) RP values were exhibited by the primer UBC881 and UBC873, respectively with the mean of 7.14 (Table 4).

The highest and the lowest EMR values of 25.00 and 14.00 were exhibited by the primer UBC815 and UBC824, respectively, with a mean of 18.34 per primer (Table 4). The number of $\mathrm{Na}$ was 2 . The mean value of the number of $\mathrm{Ne}$ is 1.40, ranging from 1.99 to 1.60 . The highest I of
0.53 and GD of 0.36 were observed from primer UBC881 followed by UBC824 with I of 0.50 and GD of 0.33 . The least I of 0.25 and GD of 0.15 were obtained from primer UBC873 followed by UBC 835 with I of 0.32 and GD of 0.20 . Allelic evenness is ranging from 0.52 to 0.79 , with a mean of 0.66 . The data obtained from each primer allowed the differentiation of a mean of 72.67 accessions per primer, ranging from 62 to 83 accessions identified (Table 4).

Table 4. Marker parameters and statistics calculated across nine ISSR primers in 96 faba bean accessions.

\begin{tabular}{ccccccccccc}
\hline Locus & EMR & PIC & MI & RP & Na & Ne & I & GD & Evenness & NG \\
\hline UBC812 & 21.04 & 0.41 & 6.35 & 6.73 & 2 & 1.36 & 0.39 & 0.24 & 0.64 & 66 \\
UBC815 & 25.00 & 0.36 & 8.96 & 11.50 & 2 & 1.47 & 0.45 & 0.30 & 0.71 & 78 \\
UBC824 & 14.00 & 0.42 & 5.85 & 6.79 & 2 & 1.54 & 0.50 & 0.33 & 0.75 & 66 \\
UBC835 & 17.00 & 0.25 & 4.22 & 4.65 & 2 & 1.30 & 0.32 & 0.20 & 0.59 & 67 \\
UBC840 & 15.00 & 0.33 & 4.97 & 6.38 & 2 & 1.44 & 0.43 & 0.28 & 0.69 & 79 \\
UBC841 & 24.00 & 0.32 & 7.60 & 8.85 & 2 & 1.38 & 0.41 & 0.26 & 0.66 & 74 \\
UBC873 & 17.00 & 0.19 & 3.18 & 2.96 & 2 & 1.20 & 0.25 & 0.15 & 0.52 & 62 \\
UBC880 & 15.00 & 0.28 & 4.22 & 4.27 & 2 & 1.33 & 0.34 & 0.21 & 0.61 & 79 \\
UBC881 & 17.00 & 0.44 & 7.46 & 12.13 & 2 & 1.60 & 0.53 & 0.36 & 0.79 & 83 \\
\hline Total & & & & & - & - & - & - & - & 654 \\
\hline Mean & 18.34 & 0.32 & 5.87 & 7.14 & 2 & 1.40 & 0.40 & 0.26 & 0.66 & 72.67 \\
\hline
\end{tabular}

EMR = effective multiplex ratio; PIC $=$ Polymorphism information content; $\mathrm{MI}=$ marker index; $\mathrm{RP}=$ resolving power, $\mathrm{Na}=$ Number of observed alleles; $\mathrm{Ne}=$ Number of effective alleles; $\mathrm{I}=$ Shannon's index; GD = Nei's gene diversity and NG = number of genotypes identified per primer.

Table 5. Genetic parameter estimates based on ISSR Marker among faba bean subpopulations.

\begin{tabular}{|c|c|c|c|c|c|c|c|}
\hline \multicolumn{8}{|c|}{ Based on Geographical Origin } \\
\hline Pop & $\mathbf{N}$ & $\% \mathbf{P}$ & $\mathrm{Na}$ & $\mathrm{Ne}$ & $\mathrm{I}$ & h & uh \\
\hline North Shewa A & 9.00 & 68.86 & 1.38 & 1.31 & 0.31 & 0.19 & 0.21 \\
\hline East Gojam & 7.00 & 57.49 & 1.15 & 1.21 & 0.23 & 0.14 & 0.15 \\
\hline West Arsi & 6.00 & 57.49 & 1.15 & 1.23 & 0.24 & 0.15 & 0.17 \\
\hline Arsi & 5.00 & 50.90 & 1.04 & 1.25 & 0.24 & 0.16 & 0.17 \\
\hline Bale & 10.00 & 55.69 & 1.11 & 1.15 & 0.19 & 0.11 & 0.11 \\
\hline North Shewa O & 6.00 & 54.49 & 1.09 & 1.23 & 0.24 & 0.15 & 0.17 \\
\hline East Hararghe & 8.00 & 72.46 & 1.45 & 1.29 & 0.30 & 0.19 & 0.20 \\
\hline West Shewa & 5.00 & 64.07 & 1.29 & 1.33 & 0.31 & 0.20 & 0.23 \\
\hline Sidama & 4.00 & 44.91 & 0.90 & 1.20 & 0.21 & 0.13 & 0.15 \\
\hline Gedeo & 11.00 & 65.27 & 1.31 & 1.20 & 0.23 & 0.14 & 0.15 \\
\hline Segen & 6.00 & 62.87 & 1.28 & 1.27 & 0.28 & 0.18 & 0.19 \\
\hline Kembata & 6.00 & 47.31 & 0.96 & 1.20 & 0.20 & 0.13 & 0.14 \\
\hline Bench Maji & 3.00 & 46.11 & 0.92 & 1.24 & 0.24 & 0.15 & 0.19 \\
\hline Central Tigray & 4.00 & 53.89 & 1.09 & 1.27 & 0.26 & 0.17 & 0.20 \\
\hline Total & 6.43 & $57.27 \%$ & 1.15 & 1.24 & 0.25 & 0.16 & 0.17 \\
\hline \multicolumn{8}{|c|}{ Based on Breeding Status } \\
\hline Landraces & 90.00 & 98.20 & 1.96 & 1.24 & 0.29 & 0.17 & 0.17 \\
\hline Released & 6.00 & 65.27 & 1.33 & 1.31 & 0.30 & 0.20 & 0.21 \\
\hline Total & 48.00 & 81.74 & 1.65 & 1.27 & 0.29 & 0.18 & 0.19 \\
\hline
\end{tabular}

$\mathrm{N}=$ number of sample, $\% \mathrm{P}=$ Percentage of Polymorphic Loci; $\mathrm{Na}=$ Number of observed Alleles; $\mathrm{Ne}=$ Number of Effective Alleles; I = Shannon's Information Index; h = expected heterozygosity, uh = Unbiased expected heterozygosity 
Table 6. Important allelic patterns for each pre-defined population.

\begin{tabular}{|c|c|c|c|c|c|c|c|}
\hline Pop & $\begin{array}{l}\text { No. } \\
\text { alleles }\end{array}$ & $\begin{array}{c}\text { No. } \\
\text { alleles } \\
\text { freq. } \geq 5 \%\end{array}$ & $\begin{array}{l}\text { No. of } \\
\text { private } \\
\text { alleles }\end{array}$ & $\begin{array}{c}\text { No. } \\
\text { LComm } \\
\text { alleles } \\
\text { freq. } \\
\leq 25 \%\end{array}$ & $\begin{array}{c}\text { No. } \\
\text { LComm } \\
\text { alleles } \\
\text { freq. } \\
\leq 50 \%\end{array}$ & $\mathrm{~h} \pm \mathrm{SD}$ & $\mathrm{uh} \pm \mathrm{SD}$ \\
\hline North Shewa A & 115 & 115 & 1 & 2 & 30 & $0.25 \pm 0.02$ & $0.28 \pm 0.02$ \\
\hline East Gojam & 96 & 96 & 0 & 2 & 15 & $0.20 \pm 0.02$ & $0.24 \pm 0.02$ \\
\hline West Arsi & 96 & 96 & 1 & 2 & 16 & $0.21 \pm 0.02$ & $0.25 \pm 0.02$ \\
\hline Arsi & 89 & 89 & 0 & 0 & 15 & $0.20 \pm 0.02$ & $0.25 \pm 0.02$ \\
\hline Bale & 93 & 93 & 0 & 1 & 17 & $0.17 \pm 0.01$ & $0.19 \pm 0.02$ \\
\hline North Shewa O & 91 & 91 & 0 & 1 & 15 & $0.20 \pm 0.02$ & $0.24 \pm 0.02$ \\
\hline East Hararghe & 121 & 121 & 5 & 4 & 30 & $0.26 \pm 0.01$ & $0.29 \pm 0.02$ \\
\hline West Shewa & 108 & 108 & 2 & 3 & 22 & $0.25 \pm 0.02$ & $0.32 \pm 0.02$ \\
\hline Sidama & 75 & 75 & 0 & 1 & 13 & $0.19 \pm 0.02$ & $0.25 \pm 0.02$ \\
\hline Gedeo & 109 & 109 & 1 & 4 & 26 & $0.21 \pm 0.01$ & $0.23 \pm 0.02$ \\
\hline Segen & 109 & 109 & 1 & 2 & 26 & $0.23 \pm 0.02$ & $0.28 \pm 0.02$ \\
\hline Kembata & 81 & 81 & 0 & 1 & 10 & $0.17 \pm 0.02$ & $0.20 \pm 0.02$ \\
\hline Bench Maji & 77 & 77 & 0 & 2 & 11 & $0.21 \pm 0.02$ & $0.31 \pm 0.03$ \\
\hline Central Tigray & 92 & 92 & 0 & 3 & 17 & $0.22 \pm 0.02$ & $0.30 \pm 0.02$ \\
\hline Released & 113 & 113 & 2 & 2 & 27 & $0.26 \pm 0.02$ & $0.31 \pm 0.02$ \\
\hline
\end{tabular}

Number of alleles, number of alleles with frequencies greater than or equal to $5 \%$, number of private alleles, number of less common alleles with frequencies less than or equal to $25 \%$ and $50 \%$, h: expected heterozygosity, uh = unbiased expected heterozygosity, $\mathrm{SD}=$ standard deviation.

Table 7. AMOVA within and among fifteen pre-defined populations.

\begin{tabular}{|c|c|c|c|c|c|c|}
\hline \multicolumn{7}{|c|}{ Based on Geographical Origin } \\
\hline Source of variation & df & SS & MS & EV & PV & P-value \\
\hline Among region & 3 & 47.51 & 15.84 & 0.00 & $0 \%$ & 0.93 \\
\hline Among populations & 10 & 225.31 & 22.53 & 0.25 & $1 \%$ & 0.25 \\
\hline Within populations & 76 & 1593.80 & 20.97 & 20.97 & $99 \%$ & 0.58 \\
\hline Total variations & 89 & 1866.62 & & 21.22 & $100 \%$ & \\
\hline \multicolumn{7}{|c|}{ Based on Breeding Status } \\
\hline Among populations & 1 & 27.67 & 27.67 & 0.57 & $3 \%$ & 0.14 \\
\hline Within populations & 94 & 1994.62 & 21.22 & 21.22 & $97 \%$ & 0.17 \\
\hline Total variations & 95 & 2022.29 & & 21.79 & $100 \%$ & \\
\hline
\end{tabular}

$\mathrm{df}=$ degrees of freedom; SS = sum of squares; MS = mean squares; EV = estimated variance, $\mathrm{PV}=$ percentage variance

\section{Population genetic diversity}

The most polymorphic loci was obtained for accessions from East Hararghe ( $\% \mathrm{P}=72.46)$ followed by accessions from North Shewa Amhara (\% P = 68.86); while accessions from Sidama and Benchi Maji showed the least percentage polymorphism $(\% \mathrm{P}=44.91)$ and $(\%$ $\mathrm{P}=46.11$ ), respectively (Table 5). Accessions from East Hararghe, North Shewa Amhara and Gedeo populations revealed the highest number of $\mathrm{Na}$. On the other hand, accessions from West Shewa, North Shewa Amhara and East Hararghe populations revealed the highest number of Ne. Similarly, accessions from West Shewa are the most diverse $(\mathrm{I}=0.31, \mathrm{~h}=0.20$, and $\mathrm{uh}=0.23)$ followed by accessions from North Shewa Amhara $(\mathrm{I}=0.31, \mathrm{~h}=0.19$, and $\mathrm{uh}=0.21)$ and East Hararghe $(\mathrm{I}=0.30, \mathrm{~h}=0.19$, and $\mathrm{uh}=0.20)$ (Table 5). Among the landrace populations evaluated, accessions from Bale $(\mathrm{I}=0.19, \mathrm{~h}=$ 0.11 , and $\mathrm{uh}=0.11)$, Kembata $(\mathrm{I}=0.20, \mathrm{~h}=0.13$, and $u h=0.14)$ and Sidama $(I=0.21, h=0.13$, and $\mathrm{uh}=0.15)$ are the least diverse (Table 5). The highest number of alleles and the number of alleles with frequencies greater than or equal to 5 $\%$ were exhibited by accessions from both East Hararghe and North Shewa Amhara populations (Table 6).

Private bands $(\mathrm{NPvB})$ were found in seven populations with East Hararghe possessing five 
$\mathrm{NPvB}$, which is the highest among all the populations. The highest number of less common alleles with frequencies less than or equal to $25 \%$ was revealed by East Hararghe populations (4) and Gedeo populations (4). Both accessions from North Shewa Amhara and East Hararghe populations also revealed the less common alleles with frequencies less than or equal to $50 \%$. Accessions from East Hararghe had the highest $h$ (0.26) followed by released variety $(0.26)$ and West Shewa (0.25). The highest uh was exhibited by West Shewa (0.32) followed by released varieties (0.31) and Central Tigray (0.30). So, having the highest number of alleles, the number of alleles with frequencies greater than or equal to $5 \%$, and the number of less common alleles with frequencies less than or equal to $50 \%$; East Hararghe and North Shewa Amhara could be the most important populations. The two populations also had the highest \% P $(72.46 \%, 68.86 \%)$, I $(0.30,0.31)$, and $h(0.19,0.19)$, respectively (Table $5)$.

\section{Analysis of molecular variance (AMOVA)}

Based on $14 \mathrm{AZs}$ that are the geographic origin of 90 landrace accessions, AMOVA revealed that the within-population variation is higher than among population variation with values of $99 \%$ and $1 \%$, respectively. Based on the breeding status that is landraces and released varieties, similarly, AMOVA revealed that the within-population variation is higher than among population variation with values of $97 \%$ and $3 \%$, respectively. Hence, in both cases, higher genetic diversity was exhibited within the population (Table 7).

\section{Cluster analysis}

Neighbor-joining (NJ) clustering analysis separated the 96 faba bean accessions into seven groups (Figure 2). The maximum and the minimum number of accessions across the seven clusters are 24 and 5 , respectively. The first cluster consisted of 12 landraces and two released varieties. Among the seven clusters; the second cluster comprised of the minimum accessions of four landraces and one released variety. While the third cluster contains the maximum accessions with 23 landraces and one released variety. The fourth and fifth clusters consisted of 13 and 14 landraces, respectively. The sixth cluster consisted of 11 landraces and one released variety. The last cluster consisted of nine landraces and one released variety (Table 8).

Table 8. Clustering 96 faba bean accessions into seven clusters using nine ISSR primers.

\begin{tabular}{|c|c|c|}
\hline Cluster & Number of accessions & Accessions \\
\hline C1 & 14 & $\begin{array}{l}\text { 30021, 26858, 25006, 30014, 26428, 220076, Lalo, 29535, } \\
208114,27052,28770 \text {, Bulga-70, 25270, } 25310\end{array}$ \\
\hline C2 & 5 & 29536, Moti, 26887, 229303, 29533 \\
\hline C3 & 24 & $\begin{array}{l}25292,26400,28104,28113,25290,29537,26853,25003, \\
219089,30015,219355,25017,25018,27929,26860,25274, \\
212565,229310, \text { Hachalu, 231293, 25298, 25010, 26889, } 30017\end{array}$ \\
\hline C4 & 12 & $\begin{array}{l}\text { Walki, 29527, 29532, 212572, 212566, 212567, 229299, 26854, } \\
\text { 26888, 212578, 28772, 25009 }\end{array}$ \\
\hline C5 & 18 & $\begin{array}{l}\text { 26886, 30016, 30022, 229871, 26883, 229869, 26885, 28110, } \\
28773,28776,208085,28774,25022,235709,25303,25299, \\
28103,16599\end{array}$ \\
\hline C6 & 13 & $\begin{array}{l}\begin{array}{l}26861,29531,220079,28777,3008,28109,30011,30023, \\
25264,26859,29526,26882,27279\end{array}\end{array}$ \\
\hline C7 & 10 & $\begin{array}{l}\text { 28771, Dagim, 26862, 27931, 220086, 26855, 28112, 25260, } \\
\text { 212580, } 25259\end{array}$ \\
\hline
\end{tabular}




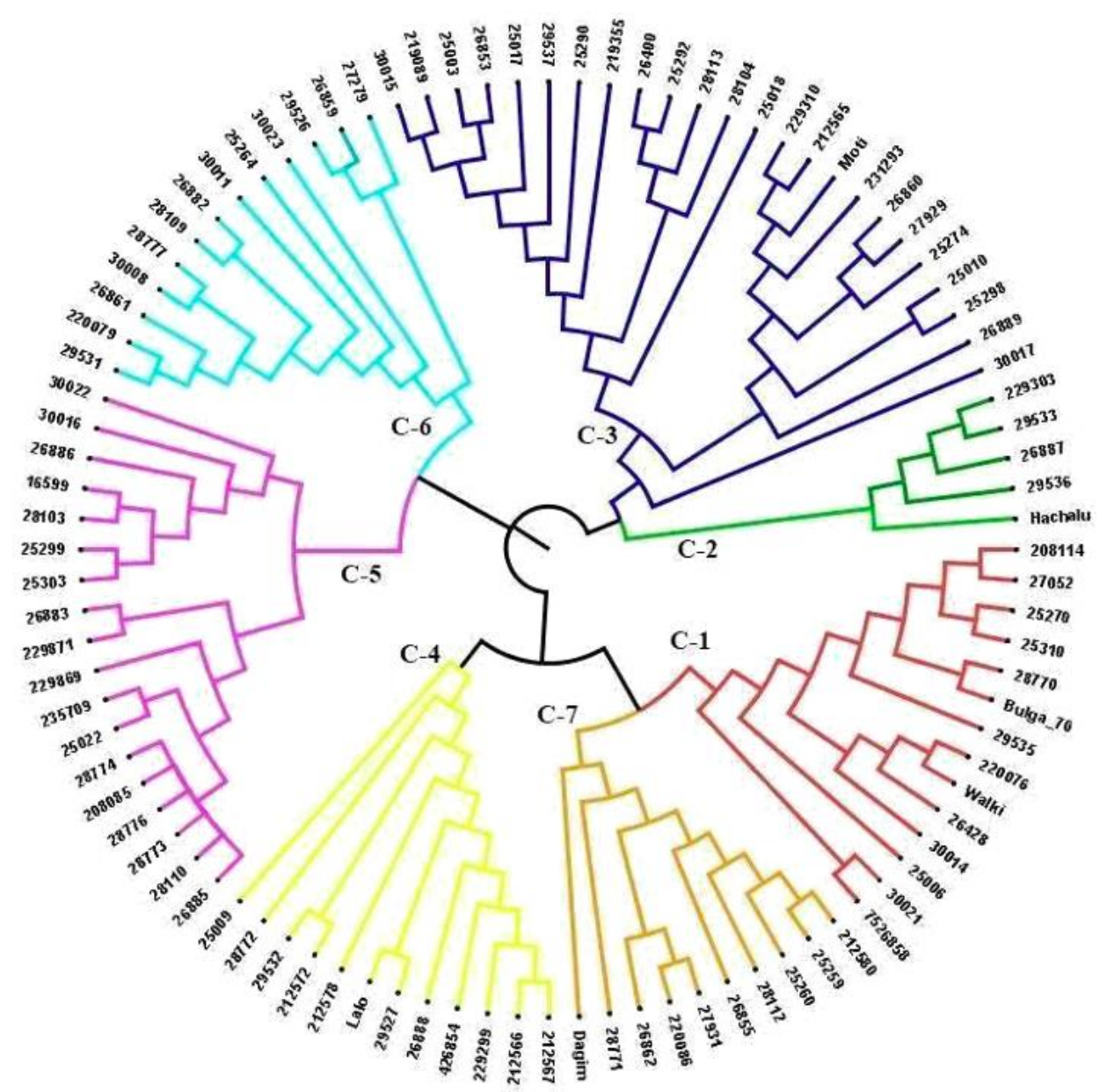

Figure 2. NJ dendrogram showing the genetic relationships for 90 faba bean landrace accessions and 6 released varieties using ISSR primers based on Nei's (1972) genetic distances.

Principal Coordinates (PCoA)

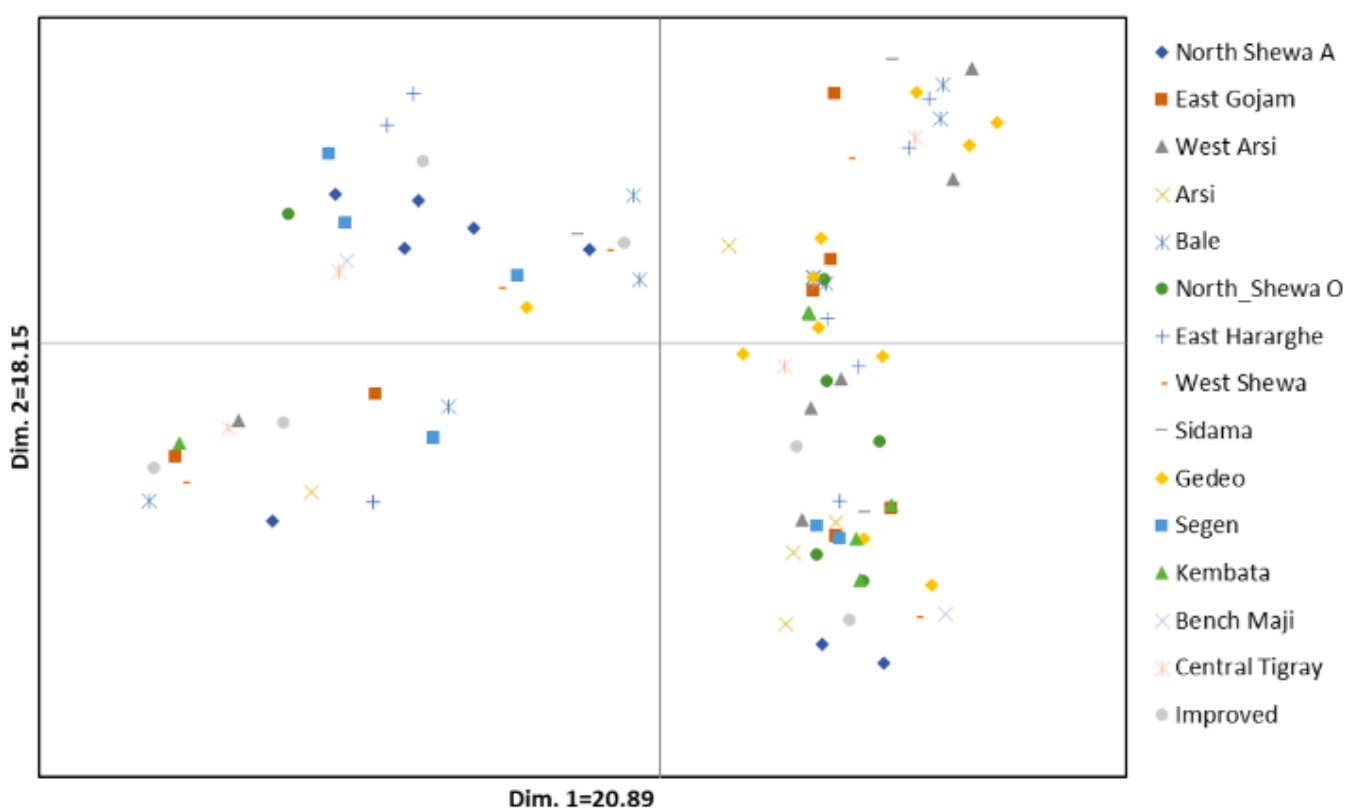

Figure 3. PCoA analysis of 96 Ethiopian faba bean accessions of fifteen pre-defined populations using ISSR data based on two-dimensional coordinates. 


\section{Principal Coordinate Analysis (PCoA)}

PCoA in the two-dimensional coordinates revealed $39.04 \%$ of the total variation, with $20.80 \%$ and $18.15 \%$ explained by PC1 and PC2, respectively (Figure 3). PCoA in the threedimensional coordinates revealed $51.23 \%$ of the total variation, with $20.80 \%, 18.15 \%$, and $12.28 \%$ explained by PC1, PC2, and PC3, respectively (Figure 4). This indicates that accessions from different AZs were clustered together in both coordinates. The clusters identified through PCoA analysis were similar to those identified in the NJ cluster analysis and also from STRUCTURE analysis thereby illustrating the conformity of results obtained from the study.

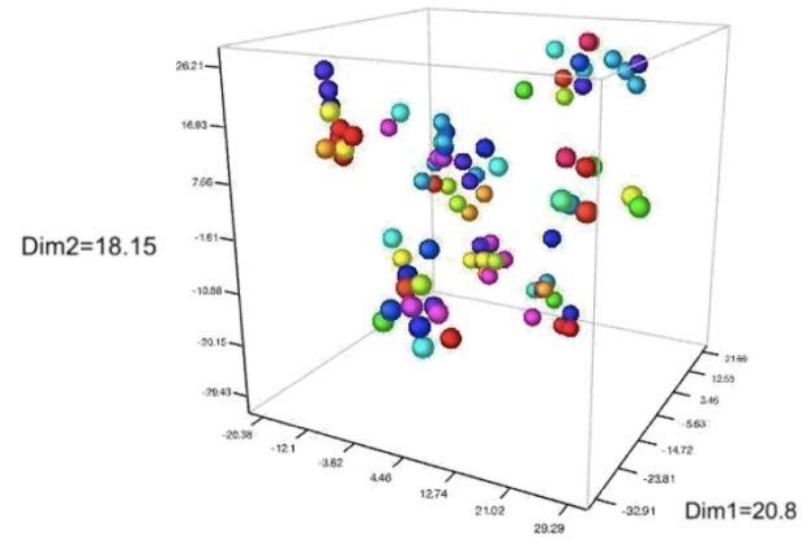

$\operatorname{Dim} 3=12.28$

Figure 4. PCoA analysis of 96 Ethiopian faba bean accessions of fifteen pre-defined populations using ISSR data based on threedimensional coordinates.

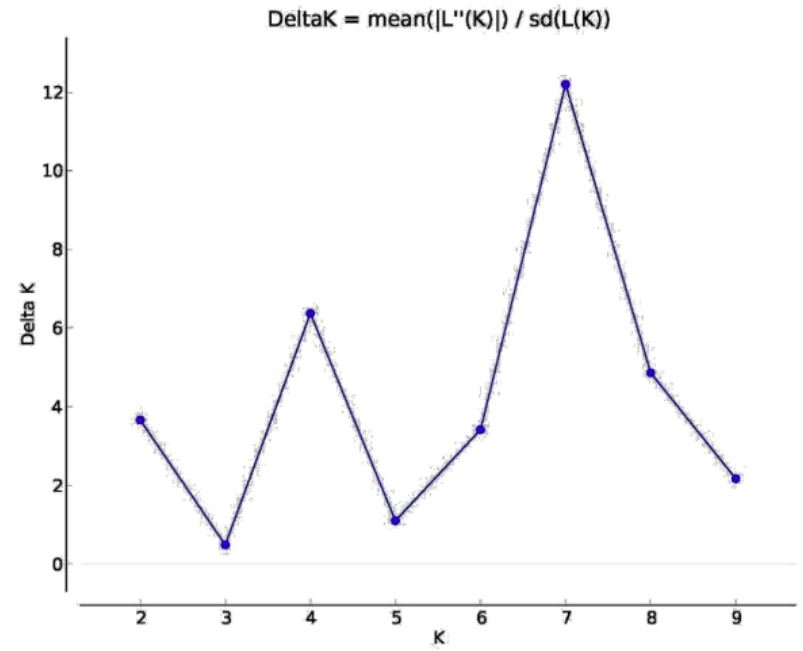

Figure 5. $\Delta \mathrm{K}$ values for each number of subpopulations $(\mathrm{K})$ for faba bean population.

\section{Population differentiation and structure Genetic distance and identity}

Genetic distance $(\mathrm{Gd})$ among the fifteen predefined populations is ranging from 0.01 to 0.04 (Table 9). Accessions from Bale were distantly related to accessions of Arsi (0.04) followed by accessions from Segen that were distantly related to accessions of Gedeo (0.04) and Bench Maji (0.04). The least $\mathrm{Gd}$ was revealed between accessions from Gedeo and Sidama populations (0.01) followed by accessions from Bale and East Gojam populations (0.01). Genetic identity (GI) coefficients using the ISSR data were used to assess the extent of genetic similarity among the 96 faba bean accessions. Genetic identity (GI) coefficients are ranging from 0.96 to 0.99 . Based on the estimated GI coefficient; the highest GI value was observed between Sidama and Gedeo (0.99) followed by East Gojam and Bale (0.99). The least GI value was observed between accessions of Arsi and Bale (0.96) followed by Gedeo and Segen (0.96).

\section{Genetic differentiation and gene flow}

Genetic differentiation (PhiPT) on faba bean landraces collected from AZs of Ethiopia revealed that PhiPT among pairs of the population are ranging from 0.00 to 0.27 , with an overall mean of 0.07 . Between Central Tigray and Bench Maji (PhiPT $=0.27$ ) population, very great PhiPT was observed. Among pair-wise populations of Bench Maji and Sidama (PhiPT=0.21), Bench Maji and West Shewa $($ PhiPT $=0.20)$, Central Tigray, and West Shewa (PhiPT $=0.18), \quad$ Sidama and West Arsi (PhiPT=0.17), and Bale and Arsi (PhiPT=0.17) large degree of PhiPT were observed. Among the Central Tigray and Sidama populations (PhiPT $=$ 0.14) moderate PhiPT was revealed. Among 105 pair-wise of PhiPT values; 52 of them ranged from $0.00-0.05,46$ of them ranged from 0.05 $0.15,6$ of them ranged from $0.15-0.25$, and 1 pair above 0.25; showing little, moderate, large, and very large PhiPT, respectively (Table 10). The gene flow of 90 faba bean landrace accessions collected from fourteen AZs including six released varieties are ranging from 0.68 to 24.75 . The highest level of gene flow $(\mathrm{Nm})$ was observed between populations of West Shewa and North Shewa Amhara; released variety and East Gojam, West Arsi, Arsi, East Hararghe; Central Tigray 
and Kembata; Segen and East Hararghe, West Shewa, Sidama, while the lowest level of $\mathrm{Nm}$ was observed between Central Tigray and Bench Maji (Table 10).

\section{Population structure}

In the present study, the number of subpopulations was determined as $(K=7)$ due to the relatively high $\Delta \mathrm{K}$ value at $\mathrm{K}=7$, according to Evanno et al. (2005) (Figure 5). The results of $\mathrm{K}=7$ populations indicated accessions from 15 pre-defined populations distributed between the seven populations as demonstrated by the bar plot (Figure 6). A vertical line broken into $\mathrm{K}$ colored segments and proportional to each of the $\mathrm{K}$ inferred clusters represent the accessions in the study. Different colors represents different subpopulations. In the figure, the accessions in the populations and the percentage identity to the cluster to which it belongs were indicated by $\mathrm{X}$ axis and $\mathrm{Y}$-axis, respectively. If a membership coefficient of the genotype is $\geq 0.80$, it belongs to a cluster but if a membership coefficient is $<0.80$, it regarded as an admixed individual. (Table 11). Among the 15 pre-defined populations; ten of them had admixed individuals with the proportion ranged from 9.09 for the Gedeo population to 40.00 for the Bale population; while the other populations do not have admixed individuals. The average proportions of admixed individuals are 13.90. Genetic divergence among clusters, expected heterozygosity within a cluster, and the proportion of the membership of each pre-defined population in each of the clusters are presented in Table 12. The maximum net nucleotide distance among the seven clusters was detected between $\mathrm{C} 1$ and $\mathrm{C} 4$ followed by $\mathrm{C} 4$ and C6, with values of 0.24 and 0.21 , respectively. While, a minimum distance was detected between C2 and C3 followed by C2 and C5, with the value of 0.10 and 0.11 , respectively. The maximum and minimum expected heterozygosity within a cluster were observed within $\mathrm{C} 2$ and $\mathrm{C} 5$, with values of 0.19 and 0.02 , respectively. Among the seven clusters; C3 and C1 exhibited the first and secondlargest proportions of 21.99 and 15.59, respectively. The minimum proportion of the membership of samples was observed in $\mathrm{C} 2$ and C6, with values of 3.66 and 8.33 , respectively.

\section{Discriminant analysis of principal components (DAPC)}

The results of the scatterplot of faba bean accessions using DAPC are exhibited in Figure 7. In the figure, the accessions and the clusters are represented by the dots and the inertia ellipses, respectively. So, based on DAPC also, the accessions were separated into seven clusters. The DAPC results in Table 12 indicated that the largest and smallest proportion of DAPC was exhibited in C6 and C2, with 0.23 and 0.05 , respectively. Both the $\mathrm{NJ}$ and the DAPC analysis classified the 96 faba bean accessions into seven clusters; even though the number of accessions in each cluster is not similar since DAPC is based on the retained discriminant functions.

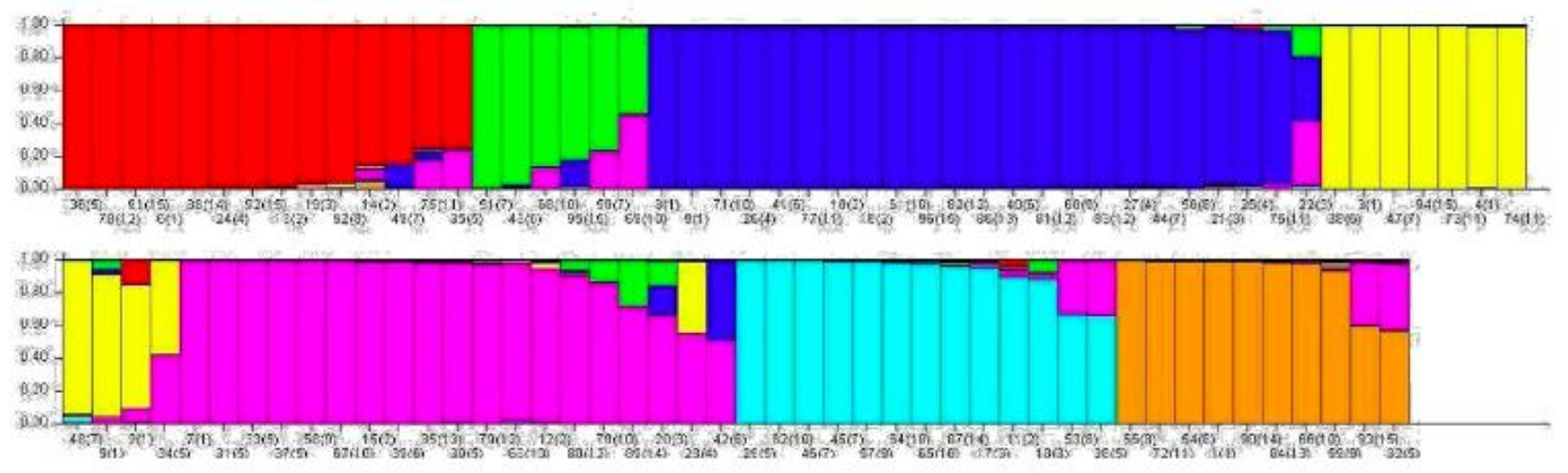

Figure 6. Classification of the 96 faba bean accessions using STRUCTURE 2.3.4 software into seven distinct clusters by the model-based method at $\mathrm{k}=7$. 
Table 9. Genetic distance (below diagonal) and Nei's genetic identity (above diagonal) among fifteen predefined populations.

\begin{tabular}{lccccccccccccccc}
\hline & NSA & EG & WA & A & B & NSO & EH & WS & SD & G & S & K & BM & CT & RV \\
\hline NSA & $* * * *$ & 0.98 & 0.98 & 0.98 & 0.98 & 0.99 & 0.98 & 0.98 & 0.98 & 0.98 & 0.98 & 0.98 & 0.98 & 0.98 & 0.98 \\
EG & 0.02 & $* * * *$ & 0.99 & 0.97 & 0.99 & 0.99 & 0.98 & 0.97 & 0.99 & 0.99 & 0.97 & 0.99 & 0.98 & 0.98 & 0.97 \\
WA & 0.02 & 0.01 & $* * * *$ & 0.97 & 0.99 & 0.99 & 0.99 & 0.98 & 0.99 & 0.99 & 0.97 & 0.98 & 0.98 & 0.98 & 0.97 \\
A & 0.02 & 0.03 & 0.03 & $* * * *$ & 0.96 & 0.98 & 0.97 & 0.97 & 0.96 & 0.96 & 0.98 & 0.98 & 0.97 & 0.97 & 0.97 \\
B & 0.02 & 0.01 & 0.01 & 0.04 & $* * * *$ & 0.98 & 0.98 & 0.97 & 0.99 & 0.99 & 0.96 & 0.98 & 0.98 & 0.98 & 0.96 \\
NSO & 0.01 & 0.01 & 0.02 & 0.02 & 0.02 & $* * * *$ & 0.99 & 0.97 & 0.98 & 0.99 & 0.98 & 0.99 & 0.98 & 0.97 & 0.97 \\
EH & 0.02 & 0.02 & 0.01 & 0.03 & 0.02 & 0.02 & $* * * *$ & 0.97 & 0.98 & 0.99 & 0.97 & 0.98 & 0.97 & 0.98 & 0.97 \\
WS & 0.02 & 0.03 & 0.02 & 0.03 & 0.03 & 0.03 & 0.03 & $* * * *$ & 0.98 & 0.97 & 0.96 & 0.97 & 0.98 & 0.98 & 0.97 \\
SD & 0.03 & 0.01 & 0.01 & 0.04 & 0.01 & 0.02 & 0.02 & 0.02 & $* * * *$ & 0.99 & 0.96 & 0.98 & 0.98 & 0.98 & 0.96 \\
G & 0.02 & 0.01 & 0.01 & 0.04 & 0.01 & 0.01 & 0.01 & 0.03 & 0.01 & $* * * *$ & 0.96 & 0.98 & 0.99 & 0.98 & 0.96 \\
S & 0.02 & 0.04 & 0.03 & 0.03 & 0.04 & 0.02 & 0.03 & 0.04 & 0.04 & 0.04 & $* * * *$ & 0.97 & 0.96 & 0.97 & 0.98 \\
K & 0.02 & 0.02 & 0.02 & 0.02 & 0.03 & 0.01 & 0.02 & 0.03 & 0.02 & 0.02 & 0.03 & $* * * *$ & 0.98 & 0.98 & 0.97 \\
BM & 0.02 & 0.02 & 0.02 & 0.04 & 0.02 & 0.02 & 0.03 & 0.03 & 0.02 & 0.02 & 0.04 & 0.02 & $* * * *$ & 0.98 & 0.97 \\
CT & 0.02 & 0.02 & 0.02 & 0.04 & 0.02 & 0.03 & 0.02 & 0.02 & 0.02 & 0.02 & 0.03 & 0.02 & 0.02 & $* * * *$ & 0.98 \\
RV & 0.02 & 0.03 & 0.03 & 0.03 & 0.04 & 0.03 & 0.03 & 0.03 & 0.04 & 0.04 & 0.02 & 0.03 & 0.03 & 0.02 & $* * * *$
\end{tabular}

$\mathrm{NSA}=$ North Shewa Amhara, EG=East Gojam, WA=West Arsi, A=Arsi, B=Bale, NSO=North Shewa Oromia, EH=East Hararghe, WS=West Shewa, SD=Sidama, $G=$ Gedeo, $S=$ Segen, $K=$ Kembata, BM=Bench Maji, CT=Central Tigray, and $\mathrm{RV}=$ Released Varieties

Table 10. PhiPT values (above diagonal) and Gene flow (Nm, below diagonal).

\begin{tabular}{lccccccccccccccc}
\hline & NSA & EG & WA & A & B & NSO & EH & WS & SD & G & S & K & BM & CT & RV \\
\hline NSA & 0 & 0.07 & 0.05 & 0.02 & 0.13 & 0.03 & 0.02 & 0.01 & 0.04 & 0.14 & 0.10 & 0.08 & 0.07 & 0.03 & 0.06 \\
EG & 3.32 & 0 & 0.11 & 0.04 & 0.04 & 0.04 & 0.00 & 0.03 & 0.11 & 0.02 & 0.03 & 0.07 & 0.12 & 0.08 & 0.01 \\
WA & 4.75 & 2.02 & 0 & 0.03 & 0.02 & 0.05 & 0.06 & 0.02 & 0.17 & 0.08 & 0.02 & 0.06 & 0.13 & 0.13 & 0.01 \\
A & 12.25 & 6.00 & 8.08 & 0 & 0.17 & 0.09 & 0.05 & 0.00 & 0.02 & 0.11 & 0.05 & 0.10 & 0.10 & 0.02 & 0.01 \\
B & 1.67 & 6.00 & 12.25 & 1.22 & 0 & 0.09 & 0.05 & 0.11 & 0.09 & 0.00 & 0.14 & 0.10 & 0.00 & 0.01 & 0.12 \\
NSO & 8.08 & 6.00 & 4.75 & 2.53 & 2.53 & 0 & 0.03 & 0.04 & 0.06 & 0.00 & 0.06 & 0.08 & 0.17 & 0.00 & 0.02 \\
EH & 12.25 & $* * * *$ & 3.92 & 4.75 & 4.75 & 8.08 & 0 & 0.01 & 0.06 & 0.00 & 0.01 & 0.05 & 0.04 & 0.08 & 0.01 \\
WS & 24.75 & 8.08 & 12.25 & $* * * *$ & 2.02 & 6.00 & 24.75 & 0 & 0.12 & 0.06 & 0.01 & 0.06 & 0.20 & 0.18 & 0.04 \\
SD & 6.00 & 2.02 & 1.22 & 12.25 & 2.53 & 3.92 & 3.92 & 1.83 & 0 & 0.13 & 0.01 & 0.03 & 0.21 & 0.14 & 0.04 \\
G & 1.54 & 12.25 & 2.88 & 2.02 & $* * * *$ & $* * * *$ & $* * * *$ & 3.92 & 1.67 & 0 & 0.12 & 0.03 & 0.10 & 0.02 & 0.12 \\
S & 2.25 & 8.08 & 12.25 & 4.75 & 1.54 & 3.92 & 24.75 & 24.75 & 24.75 & 1.83 & 0 & 0.02 & 0.09 & 0.08 & 0.06 \\
K & 2.88 & 3.32 & 3.92 & 2.25 & 2.25 & 2.88 & 4.75 & 3.92 & 8.08 & 8.08 & 12.25 & 0 & 0.09 & 0.01 & 0.05 \\
BM & 3.32 & 1.83 & 1.67 & 2.25 & $* * * *$ & 1.22 & 6.00 & 1.00 & 0.94 & 2.25 & 2.53 & 2.53 & 0 & 0.27 & 0.11 \\
CT & 8.08 & 2.88 & 1.67 & 12.25 & 24.75 & $* * * *$ & 2.88 & 1.14 & 1.54 & 12.25 & 2.88 & 24.75 & 0.68 & 0 & 0.13 \\
RV & 3.92 & 24.75 & 24.75 & 24.75 & 1.83 & 12.25 & 24.75 & 6.00 & 6.00 & 1.83 & 3.92 & 4.75 & 2.02 & 1.67 & 0 \\
\hline
\end{tabular}


Table 11. The proportion of the membership of each fifteen pre-defined population in each of the clusters.

\begin{tabular}{lccccccccc}
\hline \multirow{2}{*}{ Population } & $\begin{array}{c}\text { Number } \\
\text { of }\end{array}$ & \multirow{2}{*}{$\begin{array}{c}\text { Admixed } \\
\text { individual }\end{array}$} & \multicolumn{6}{c}{ The proportion of membership in each cluster (\%) } \\
\cline { 7 - 11 } & accessions & & C2 & C3 & C4 & C5 & C6 & C7 \\
\hline North Shewa A & 9.00 & 11.11 & 11.11 & 0.00 & 22.22 & 33.33 & 11.11 & 0.00 & 11.11 \\
East Gojam & 7.00 & 0.00 & 28.57 & 0.00 & 28.57 & 0.00 & 42.86 & 14.29 & 0.00 \\
West Arsi & 6.00 & 33.33 & 16.67 & 0.00 & 16.67 & 0.00 & 0.00 & 33.33 & 0.00 \\
Arsi & 5.00 & 20.00 & 60.00 & 0.00 & 20.00 & 0.00 & 0.00 & 0.00 & 0.00 \\
Bale & 10.00 & 40.00 & 10.00 & 0.00 & 0.00 & 0.00 & 40.00 & 10.00 & 10.00 \\
North Shewa O & 6.00 & 16.67 & 0.00 & 16.67 & 33.33 & 16.67 & 16.67 & 0.00 & 0.00 \\
East Hararghe & 8.00 & 0.00 & 12.50 & 12.50 & 12.50 & 25.00 & 0.00 & 25.00 & 0.00 \\
West Shewa & 5.00 & 20.00 & 20.00 & 0.00 & 20.00 & 0.00 & 0.00 & 0.00 & 40.00 \\
Sidama & 4.00 & 0.00 & 0.00 & 0.00 & 25.00 & 0.00 & 25.00 & 25.00 & 25.00 \\
Gedeo & 11.00 & 9.09 & 0.00 & 9.09 & 18.18 & 0.00 & 27.27 & 27.27 & 9.09 \\
Segen & 6.00 & 16.67 & 0.00 & 0.00 & 33.33 & 33.33 & 0.00 & 0.00 & 16.67 \\
Kembata & 6.00 & 0.00 & 16.67 & 0.00 & 50.00 & 0.00 & 33.33 & 0.00 & 0.00 \\
Bench Maji & 3.00 & 0.00 & 0.00 & 0.00 & 33.33 & 0.00 & 33.33 & 0.00 & 33.33 \\
Central Tigray & 4.00 & 25.00 & 25.00 & 0.00 & 0.00 & 0.00 & 0.00 & 25.00 & 25.00 \\
Released & 6.00 & 16.67 & 33.33 & 16.67 & 16.67 & 16.67 & 0.00 & 0.00 & 0.00 \\
\hline
\end{tabular}

Table 12. Genetic divergence among the clusters (net nucleotide distance), within the clusters (expected heterozygosity), and proportion of the accessions in each of the clusters.

\begin{tabular}{ccccccccccc}
\hline \multicolumn{7}{c}{ Net nucleotide distance } & $\begin{array}{c}\text { Expected } \\
\text { heterozygosity }\end{array}$ & $\begin{array}{c}\text { Proportion of } \\
\text { membership }\end{array}$ & DAPC \\
\hline & C1 & C2 & C3 & C4 & C5 & C6 & C7 & \\
C1 & - & 0.17 & 0.18 & 0.19 & 0.20 & 0.24 & 0.18 & 0.12 & 15.59 & 0.12 \\
C2 & & - & 0.10 & 0.17 & 0.11 & 0.14 & 0.16 & 0.19 & 3.66 & 0.05 \\
C3 & & - & 0.20 & 0.14 & 0.19 & 0.17 & 0.14 & 21.99 & 0.14 \\
C4 & & & - & 0.20 & 0.21 & 0.19 & 0.12 & 8.33 & 0.10 \\
C5 & & & & - & 0.16 & 0.18 & 0.02 & 15.31 & 0.22 \\
C6 & & & & & - & 0.18 & 0.12 & 10.66 & 0.23 \\
C7 & & & & & & - & 0.16 & 11.35 & 0.15 \\
\hline
\end{tabular}

\section{DISCUSSION}

The ISSR markers amplified a total of 167 different types of bands. The average total bands per primer were 18.56; ranging from 14 to 25 with all $100 \%$ polymorphism. In contrast to this study, Terzopoulosa and Bebeli (2008) reported an average percent of polymorphisms of $67.48 \%$ by using 11 ISSR primers in studying the genetic diversity of the Greek faba bean population. Abdel-razzak et al. (2012) also reported an average percent of polymorphisms of $69.10 \%$ within 10 faba bean genotypes from Egypt using nine ISSR primers. Moreover, Merji et al. (2012) found $97.30 \%$ average polymorphism in the analysis of the effect of gamma radiation on various characters of 22 faba bean genotypes grown in Tunisia using 15 ISSR primers. Similarly, using ISSR markers, the study on global faba bean germplasm by Wang et al. (2012) indicated an average percentage of polymorphism of $93 \%$. The present study exhibited a higher average percentage of polymorphism than the finding reported by all authors, which could be explained by the diversified nature of landrace accessions and also a large number of accessions used. Therefore, the higher average percent of polymorphism resulted in current study indicates the use of ISSR markers for future genetic diversity studies.

PIC, MI, and RP measure the efficiency of ISSR markers, as described by Roldan-Ruiz et al. (2000), Varshney et al. (2007), and Prevost and 
Wilkinson (1999), respectively. The highest and the lowest PIC values of 0.44 and 0.19 were revealed by the primers UBC881 and UBC873, respectively, with a mean of 0.32 . Similar to the current study, Ya-ming et al. (2011) and Abdollah et al. (2011) found average PIC values of 0.29 and 0.22 , respectively. The high PIC values for ISSR primers in this study indicates the suitability and efficiency of the markers in the assessment of genetic diversity of faba bean landrace accessions in Ethiopia. In detecting polymorphism, MI is also calculate the efficiency of the markers. MI in the current study is ranging from 3.18 to 7.46, with an average of 5.87 in nine ISSR primers, which is higher than MI described by Abdollah et al. (2011) with an average of 1.34. In the current study, the high value of MI was derived from the high average EMR value of 18.38. In contrast to the current study, Abdolla et al. (2011) found an average EMR value of 5.69. The discriminatory power of ISSR markers is measured by RP. The mean value of RP is 7.14 , ranging from 2.96 to 12.13. Similarly, Abdolla et al. (2011) reported RP values ranging from 7.20 to 16.50 . Hence, the result in the current study confirmed that the suitability, efficiency, and discriminatory power of the ISSR markers, and they would be recommended for further diversity analysis..

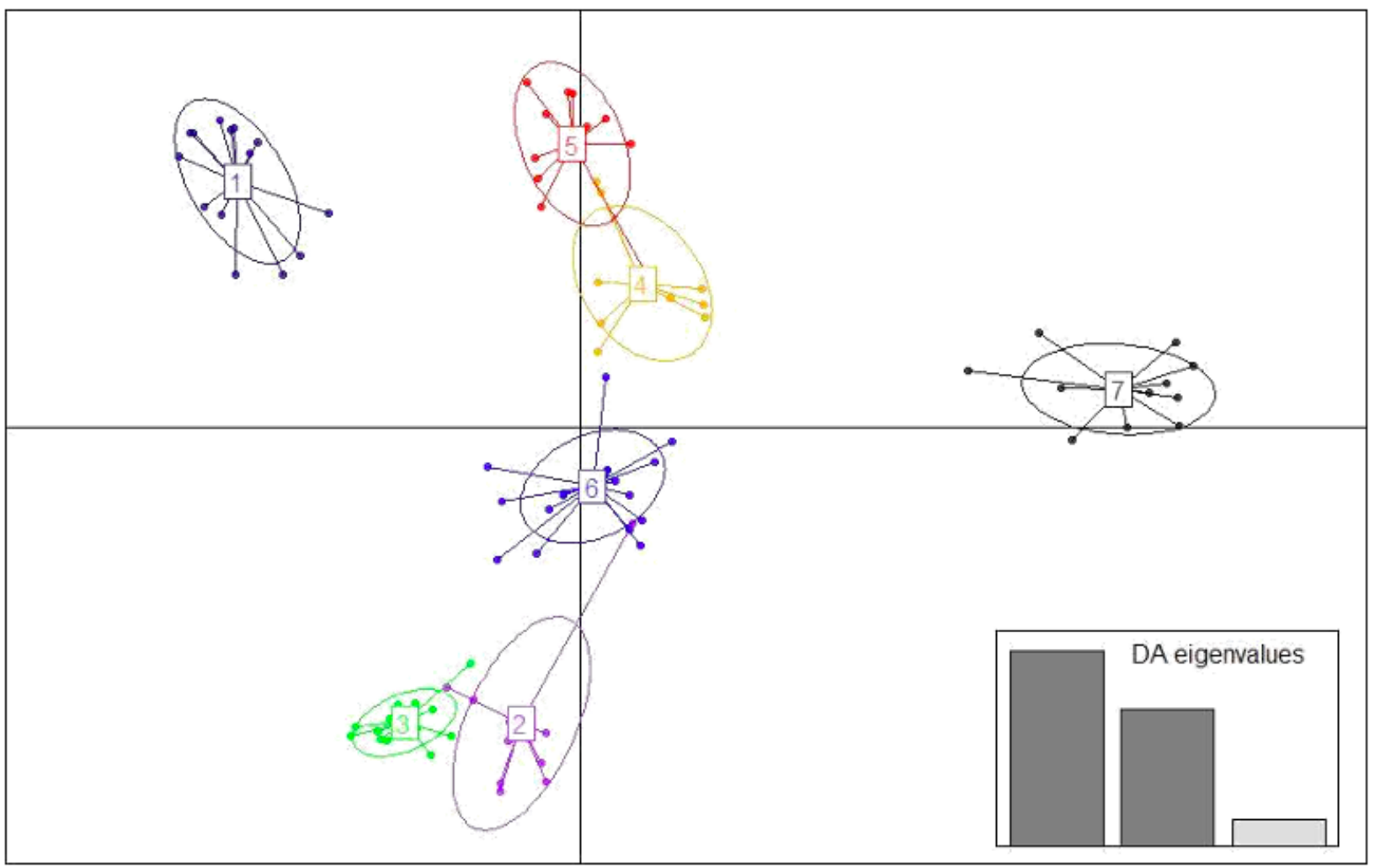

Figure 7. A scattered plot of 96 faba bean accessions using DAPC based on ISSR data.

The degree of polymorphism among the breeding status of faba bean accessions ranged from 65.27 for the released varieties to 98.20 for the landrace accessions. The highest polymorphism observed in the landrace accessions as compared to the released varieties could be explained by the broader spectrum of landrace accessions as a reservoir of different alleles. The present study revealed moderate diversity indexes $(I=0.25$, and $\mathrm{h}=0.16)$ values for the faba bean landrace accessions as compared to gene diversity indexes $(\mathrm{I}=0.53$, and $\mathrm{h}=0.35)$ reported by Abdel-Razak et al. (2012) who studied faba bean using ISSR markers. Accessions from West Shewa followed by North Shewa Amhara and East Hararghe were found to be high diversity as opposed to those from the other AZs. Hence, further collection, conservation, and utilization programs would be carried out from AZs with high genetic diversity. The study of genetic distance between fifteen predefined populations would also be important for accessions improvement. The present study showed the highest inter-population genetic distance between Bale and Arsi populations as 
compared to the other pair-wise distance values. As a result, hybridization between accessions from distantly related populations of Bale and Arsi is supposed to yield higher hybrids as compared to less distantly related populations.

AMOVA revealed that the variation within a population and among a population of $99 \%$ and $1 \%$, respectively. Similarly, Oliviera et al. (2006) observed $81 \%$ within a population and 19\% among-population variation in genetic diversity and structure analysis using 26 nuclear SSRs. According to Behailu (2016) the variation within a population and among a population of $91 \%$ and $9 \%$, respectively, were reported in genetic diversity study of 32 Ethiopian faba bean varieties using ISSR markers. Hence, this study showed that variation within populations is large in faba bean. Jin et al. (2006) and Belaid et al. (2006) have also reported similar results on Glycine max and Lathyrus sativus populations, respectively. The high level of genetic variation within populations as compared to among populations may be the transfer of seeds among AZs by a farmer to farmer seed exchange, during harvesting, through the market, and exchange of seeds through relief agencies like NGOs. Faba bean growers in Ethiopia get their seed mostly by the informal seed exchange system. In this line, there has been a lot of genetic exchange among farmers' landrace for seed (Alemu et al., 2010). The partially allogamous nature of faba bean could also be the other possible factor for high genetic variation within groups. Because, the pollen of faba bean can easily move by insect pollinators like bee and bee beetles causing outcrossing of the varieties (Ellwood et al., 2008). Hence, high genetic variation within populations indicates the existence of high gene flow among pre-defined populations.

The current study grouped the AZs based on 14 pre-defined populations into seven clusters using ISSR primers based on NJ which had the potential to detect genetic variability in faba bean accessions. This is similar to Abdel-razzak et al. (2012) who studied genetic diversity in ten faba bean genotypes from Egypt using ISSR clustered the individuals depending on their genetic similarity rather than their geographical origin.

Wang et al. (2012) also reported the clustering of genotypes from different origins into the same cluster without showing a clear-cut category. In this study, accessions from similar AZs were separated into different clusters and also accessions from different AZs were clustered together showing the existence of variation within a population. So, the analysis of the NJ tree showed no clear-cut pattern about the geographical origin, which could be due to higher gene flow between pre-defined populations. Similar to Keneni et al. (2005) report on local field pea and faba bean accessions, the current study revealed the separation of accessions from nonneighboring populations into the same clusters. The PCoA results revealed that the first two and three axes represent $39.04 \%$ and $51.23 \%$, respectively, of the total variability. The result of PCoA in both two-dimensional and threedimensional coordinates were similar to NJ result indicating the conformity of the results obtained from the study.

The degree of population differentiation was measured with PhiPT. According to Wright (1978), a PhiPT value greater than 0.25 is referred to as very great PhiPT, a PhiPT within 0.15 to 0.25 is referred to as a large PhiPT, a PhiPT within 0.05 to 0.15 is referred to as moderate PhiPT, and values lying within 0.00 to 0.05 considered little PhiPT. In the present study, the values of most of the pair-wise comparisons among the fifteen predefined populations were ranging from little to moderate PhiPT. Waples (1987) categorized Nm into three that are $\mathrm{Nm} \geq 1$ is referred to as high, $\mathrm{Nm}$ value within $0.25-0.99$ is referred to as intermediate, and $\mathrm{Nm}$ value within $0.00-0.25$ is referred to as low. According to Wright (1951) if $\mathrm{Nm}>1$, the PhiPT is little, and if $\mathrm{Nm}<1$, the PhiPT is high. If $\mathrm{Nm}>1$, PhiPT does not results from genetic drift only, but if $\mathrm{Nm}<1$ it results from genetic drift only (Slatkin, 1987). So, in this study, the relatively little to moderate PhiPT and high level of $\mathrm{Nm}$ detected strongly indicate that the exchange of genetic materials between 15 predefined populations is sufficient to counter the genetic composition of the population.

To confirm their complementarity, the STRUCTURE and DAPC were also used to analyze the population structure of 96 faba bean accessions. However, the variation between NJ and DAPC in grouping accessions into clusters is; NJ method is based on the agglomerative hierarchical method of clustering, and DAPC is based on the non-hierarchical clustering method 
(Campoy et al. 2016). The STRUCTURE analysis also agreed with the dendrogram analysis in that seven clusters were found in the population. The complementarity of this result suggests the representative nature of the used markers. Wang et al. (2012) reported similar results with the current study that is the congruency between dendrogram and PCoA results.

\section{CONCLUSION}

Faba bean plays a significant role in both the human diet and animal feed since it has high protein and starch content in its seeds. Determining genetic diversity is an important element of crop improvement programs. Although there are more than 2,300 faba bean accessions in the Ethiopian Biodiversity Institute; its molecular genetic diversity has not been comprehensively studied. In the current study, the molecular genetic diversity of Ethiopian faba bean landrace accessions was estimated using nine ISSR primers. The present study detected a higher percent of polymorphism as compared to other studies based on faba bean using ISSR primers and also different markers on other legume crops. Furthermore, it also showed that based on different diversity indices faba bean landraces accessions possess a wide range of genetic diversity within AZs, indicating its importance for further collection and utilization programs. The current finding displays the presence of high genetic diversity in the Ethiopian faba bean landrace accessions across the geographic regions. The high genetic diversity within the population as compared to the population is due to the high gene flow between the AZs. Based on the primers' performance of the nine ISSR markers; PIC, MI, $\mathrm{RP}$, and EMR parameters were able to detect a substantial level of genetic diversity in faba bean landrace accessions and it would also be recommended for use in faba bean improvement programs. Landrace accessions from 14 AZs of the country were distributed over the majority of the clusters, exhibiting high genetic diversity in most of the collection sites. As a result, further collection, conservation, and utilization programs would be recommended from AZs with high genetic diversity.

\section{ACKNOWLEDGEMENTS}

The authors are grateful to the EBI for providing faba bean landrace accessions; DbARC and HARC for providing released varieties. We also appreciated Dr.Kassahun Tesfaye for permitting the use of the plant genetic laboratory of AAU.

\section{REFERENCES}

Abdel-Razzak, H. S., Alfrmawy, A. M., Ibrahim, H. M., \& ElHanafy, A. 2012. Genetic diversity in faba bean (Vicia faba L.) using inter simple sequence repeat (ISSR) markers and protein analysis. Journal of Life Science 9 (2): 497-503.

Abdollah, N., Reza, A. P., \& Ezatollah, F. 2011. Evaluation of genetic diversity in wheat cultivars and breeding lines using inter simple sequence repeat markers. Biotechnology \& Biotechnological Equipment 25 (4): 2634-2638.

Alemu, D., Rashid, S, \& Tripp, R. 2010. Seed system potential in Ethiopia: Constraints and opportunities for enhancing the seed sector. International Food Policy Research Institute CGIAR, Addis Ababa.

Behailu Mulugeta. 2016. Genetic diversity study of Ethiopian faba bean (Vicia faba L.) varieties using phenotypic traits, ISSR, and SNP markers. An MSc thesis, Addis Ababa University, Addis Ababa, Ethiopia.

Bhagyawant, S. \& Srivastava, N. 2008. Genetic fingerprinting of chickpea (Cicer arietinum L.) germplasm using ISSR markers and their relationships. African Journal of Biotechnology 7 (24): 428-443.

Borsch, T., Hilu, K. W., Quandt, D., Wilde, V., Neinhuis, C., \& Barthlott, W. 2003. Noncoding plastid trnT-trnF sequences reveal a well-resolved phylogeny of basal angiosperms. Journal of Evolutionary Biology 16: 558-576.

Campoy, J. A., Lerigoleur-Balsemin, E., Christmann, H., Beauvieux, R., Girollet, N., Quero García, J., Dirlewanger, E., \& Barreneche, T. 2016. Genetic diversity, linkage disequilibrium, population structure, and construction of a core collection of Prunus avium L. landraces and bred cultivars. BMC Plant Biology 16: 49.

Caracuta, V., Barzilai, O., Khalaily, H., Milevski, I., Paz, Y., Vardi, J., Regev, L. \& Boaretto, E. 2015. The onset of faba bean farming in the Southern Levant. Scientific Reports 5 (14370).

Central Statistical Agency (CSA). 2014. Report on area and production of major crops (private peasant holdings, meher season). Statistical Bulletin 532, CSA, Addis Ababa, Ethiopia.

Central Statistical Agency (CSA). 2018. Agricultural Sample Survey 2017/2018 (2010 E.C.): Report on Area and Production of Crops (Private Peasant Holdings, Meher Season). Central Statistical Agency Ethiopia, Addis Ababa, Ethiopia. Statistical Bulletin: 586.pp.57

Chintalapati, P. 2001. The Shift to Cereal Monocropping, a Threat or a Blessing: Towards Sustainable Agricultural Production in the Highlands of Southeast Oromia, Ethiopia. ICRA, Ethiopia, Pages: 189.

Duc, G., S. Bao, M. Baum, B. Redden, M. Sadiki, M. J. Suso et al. 2010. Diversity maintenance and use of Vicia faba L. genetic resources. Field Crops Research 115: 270-278.

Ellwood, S. R., Phan, H. T., Jordan, M., Hane, J., Torres, A. M., Avila, C. M., Cruz- Izquierdo, S. \& Oliver, R. P. 2008. Construction of a comparative genetic map in faba bean 
(Vicia faba L.); conservation of genome structure with Lens culinaris. BMC Genomics 9: 380-391.

Evanno, G., Regnaut, S., \& Goudet, J. 2005. Detecting the number of clusters of individuals using the software structure: A simulation study. Molecular Ecology 14(8): 2611-2620.

Excoffier, L., Laval, G., \& Schneider, S. 2006. An integrated software package for population genetics data analysis. Computational and Molecular Population Genetics Lab (CMPG), Institute of Zoology, University of Berne, Switzerland.

FAOSTAT. 2014. Data base. Available at: http://faostat3.fao.org/faostat-gateway.

Gemechu, K., Mussa, J., Tezera, W., \& Getnet, D. 2005. Extent and pattern of genetic diversity for morpho-agronomic traits in Ethiopian highland pulse landraces: I. Field pea (Pisum sativum L.). Genetic Resource Crop Evolution 52: 539-549.

Gong, Y., Xu, S., \& Mao, W. 2011. Genetic diversity analysis of faba bean (Vicia faba L.) based on EST-SSR markers. Agricultural Science China 10: 838-844.

Hammer, O., Harper, D. A., \& Ryan, P. D. 2001. PAST: Paleontological statistics software package for education and data analysis. Palaeontologia Electronica 4: 9.

Harlan, J. R. 1969. Ethiopia: a center of diversity. Economic Botany 23: 309-314.

Jakobsson, M. \& Rosenberg, N. A. 2007. CLUMPP : a cluster matching and permutation program for dealing with label switching and multimodality in analysis of population structure. Bioinformatics 23: 1801-1806.

Jin, Y., He, T. \& Lu, B. R. 2006. Genetic spatial clustering: significant implications for conservation of wild soybean (Glycine soja: Fabaceae). Genetica 128: 41-49.

Jombart, T., Devillard, S., \& Balloux, F. 2010. Discriminant analysis of principal components: a new method for the analysis of genetically structured populations. BMC Genetics 11: 1-15.

Joseph, S. \& David, W. 2001. Molecular cloning. A Laboratory Manual ( $3^{\text {rd }}$ ed.). Cold Spring Harbor, N.Y. Cold Spring Harbor Laboratory Press. ISBN 978-0-879-69576-7.

Kamvar, Z. N., Tabima, J. F., \& Grünwald, N. J. 2014. Poppr: an $\mathrm{R}$ package for genetic analysis of populations with clonal, partially clonal, and/or sexual reproduction. Peer Journal 2: 281

Kaur, S., et al. 2014. SNP discovery and high-density genetic mapping in faba bean (Vicia faba L.) permits identification of QTLs for ascochyta blight resistance. Plant Science $217-$ 218: 47-55.

Kwon, S. J., Jinguo, H., \& Clarice, J. C. 2010. Genetic diversity and relationship among faba bean (Vicia faba L.) germplasm entries as revealed by TRAP markers. Plant Genetic Resources Sour 8: 204-213.

Lawes, D. A, Bond, D. A., \& Poulsen, M. H. 1983. Classification, origin, breeding methods and objectives. In: Hebblethwaite PD (ed). The faba bean (Vicia faba L.) A basis for improvement. Butterworth's, London, England, pp.23-67.

Ma, Y., Yang, T., Guan, J., Wang, S., Wang, H., Sun, X., \& Zong, X. 2011. Development and characterization of 21 ESTderived microsatellite markers in Vicia faba (fava bean). American Journal of Biotechnology 98 (2):22-40.

Marzinzig, B., Brünjes, L., Biagioni, S., Behling, H., Link, W., \& Westphal, C. 2018. Bee pollinators of faba bean (Vicia faba L.) differ in their foraging behavior and pollination efficiency. Agriculture, Ecosystems \& Environment 264: 24-33.

Mejri, S., Mabrouk, Y., Voisin, M., Delavault, P. H., Simier, P. H., Saidi, M., \& Belhadj, O. 2012. Variation in quantitative characters of faba bean after seed irradiation and associated molecular changes. African Journal of Biotechnology 11 (33): 8383- 8390
Nei, M. 1972. Genetic distance between populations, The American Naturalist 106: 283-292.

Panwar, P., Manoj, N., Vijay, K., \& Anil, K. 2010. Comparative evaluation of genetic diversity using RAPD, SSR and cytochrome P450 gene based markers with respect to calcium content in finger millet (Eleusine coracana L. Gaertn). Journal of Genetics 89: 121-133.

Pavlicek, A., Hrda, S., \& Flegr, J. 1999. Free-tree-software program for construction of phylogenetic trees based on distance data and bootstrap/jackknife analysis of the tree robustness. Application in the RAPD analysis of genus Frenkelia. Folia Biology (Praba) 45: 97-99.

Peakall, R. R. \& Smouse, P. E. 2012. GenALEx 6.5: genetic analysis in Excel. Population genetic software for teaching and research update. Bioinformatics 28 (19): 2537-2539.

Prevost, A. \& Wilkinson. J. 1999. A new system of comparing PCR primers applied to ISSR fingerprinting of potato cultivars. Theoretical and Applied Genetics 88 (1): 107-112.

Pritchard, J. K., Stephens, M., \& Donnelly, P. 2000. Inference of population structure using multilocus genotype data. Genetics 155 (2): 945-959.

Rohlf, F. J. 2000. NTSYS-pc ver 2.11T. Exter Software, Setauket, New York.

Roldàn-Ruiz, I., Dendauw, J., Van Bockstaele, E., Depicker, A., \& De Loose, M. 2000. AFLP markers reveal high polymorphic rates in ryegrasses. Molecular Breeding 6(2): 125 134.

Rosenberg, N. A. 2004. DISTRUCT : a program for the graphical display of population structure. Molecular Ecology 4: 137-138.

Saitou, N. \& Nei, M. 1987. The neighbor-joining method: A new method for reconstructing phylogenetic trees. Molecular Biology Evolution 4: 406-425.

Sneath, P. H. \& Sokal, R. R. 1973. Numerical taxonomy, W. H. Freedom and Co. San Francisco Statistica Stat Soft, Inc. 2001. STATISTICA (data analysis software system) Version 6.0.

Studier, J. A. \& Keppler, K. L. 1988. A note on the neighborjoining algorithm of Saitou and Nei. Molecular Biology and Evolution 5: 729-731.

Varshney, R. K., Chabane, K., Hendre, P. S., Aggarwal, R. K., \& Graner, A. 2007. Comparative assessment of EST-SSR, ESTSNP, and AFLP markers for evaluation of genetic diversity and conservation of genetic resources using wild, cultivated, and elite barleys, Journal of Plant Sciences 173 (6): 638-649.

Wang, H., Zong, X., Guan, J., Yang, T., Sun X., Ma, Y. \& Redden, R. 2012. Genetic diversity and relationship of global faba bean (Vicia faba L.) germplasm revealed by ISSR markers. Theoretical and Applied Genetics 124 (7): 789-797.

Yahia, Y, Hannachi, H., \& Monforte, A. J. 2014. Genetic diversity in Vicia faba L. populations cultivated in Tunisia revealed by simple sequence repeat analysis. Plant Genet Resource 12:278285.

Ya-ming, G., X. Sheng-chun, M. Wei-hua, L. Ze-yun, H. Qi-zan, \& Z. Gu-wen, 2011. Genetic Diversity Analysis of Faba Bean (Vicia faba L.) Based on EST-SSR Markers. Agricultural Sciences in China 10: 838-844.

Yeh, F., Yang, R., \& Boyle, T. 1999. Population genetic analysis of co-dominant markers and qualitative traits. Belgium Journal of Botany 129: 157.

Yohannes, D. 2000. Faba bean (Vicia faba) in Ethiopia. Institute of Biodiversity and Conservation Research (IBCR), Addis Ababa, Ethiopia. 